\title{
Transcranial Direct Current Stimulation and Sports Performance
}

\begin{abstract}
Dylan J. Edwards ${ }^{1,2,3,4 *}$, Mar Cortes ${ }^{5,6}$, Susan Wortman-Jutt ${ }^{7}$, David Putrino ${ }^{6,8}$, Marom Bikson ${ }^{9}$, Gary Thickbroom ${ }^{1,3,6}$ and Alvaro Pascual-Leone ${ }^{2,10}$

${ }^{1}$ Non-Invasive Brain Stimulation and Human Motor Control Laboratory, Burke Medical Research Institute, Weill Cornell Graduate School of Medical Sciences, Cornell University, White Plains, NY, USA, ${ }^{2}$ Berenson-Allen Center for Noninvasive Brain Stimulation, Beth Israel Deaconess Medical Center, Harvard Medical School, Boston, MA, USA, ${ }^{3}$ School of Medical and Health Sciences, Edith Cowan University, Perth, WA, Australia, ${ }^{4}$ Department of Neurology, Weill Cornell Graduate School of Medical Sciences, Cornell University, New York, NY, USA, ${ }^{5}$ Human Spinal Cord Injury Repair Laboratory, Burke Medical Research Institute, Weill Cornell Graduate School of Medical Sciences, Cornell University, White Plains, NY, USA, ${ }^{6}$ Department of Rehabilitation Medicine, Weill Cornell Graduate School of Medical Sciences, Cornell University, New York, NY, USA, ${ }^{7}$ Burke Rehabilitation Hospital, White Plains, NY, USA, ${ }^{8}$ Telemedicine and Virtual Rehabilitation Laboratory, Burke Medical Research Institute, White Plains, NY, USA, ${ }^{9}$ Department of Biomedical Engineering, City College of New York, City University of New York, New York, NY, USA, ${ }^{10}$ Institut de Neurorehabilitacio Guttman, Universitat Autonoma de Barcelona, Badalona, Spain
\end{abstract}

Keywords: tDCS, DIY, brain, sports, athletes

The application of transcranial direct current stimulation (tDCS) has moved from the laboratory to the wider community. This form of non-invasive brain stimulation has been shown in a number of controlled animal and human experiments, over nearly five decades, to modulate brain physiology, cognitive functions, and behavior. While its effects are variable across and within individuals, it is not unreasonable to state that tDCS harbors the potential to enhance executive and physical human performance. In a society increasingly driven to succeed with less effort, performance enhancement with an intervention that has an excellent safety record, is well tolerated, relatively inexpensive and readily available, is particularly appealing. Here, we offer a perspective on tDCS for the enhancement of physical performance in sport. The ethical and legal implications of the transition of tDCS from academic experimental work to general-public use, are discussed elsewhere (Janssens and Kraft, 2012; Bain et al., 2015; Fregni et al., 2015; Bikson et al., 2016a; Kuersten and Hamilton, 2016; Zettler, 2016).

We know from modeling (Datta et al., 2009; Luu et al., 2016), imaging (Baudewig et al., 2001; DosSantos et al., 2012; Jog et al., 2016), intra-cranial recording (Huang et al., 2017), and physiological studies (Nitsche and Paulus, 2000; Edwards et al., 2013; Strube et al., 2016) that the electrical current from tDCS can penetrate the skull to influence neural tissue and vasculature (Hamner et al., 2015). A good way to intuit that small amounts of current can transverse the skull is to recognize that the electroencephalogram (EEG) represents current passage in the reverse direction (Wagner et al., 2016). We also know that under laboratory conditions (Woods et al., 2016), the safety profile of tDCS is excellent, including in people with neurological and other disorders (Bikson et al., 2016b) although its safety for repeated and prolongued use in healthy individuals has yet to be confirmed (Wexler, 2016; Angius et al., 2017).

The spread of tDCS outside controlled laboratory conditions, fueled to some extent by media attention and high-profile users, has created concerns among some tDCS researchers. Recently we have seen the publication of an open letter recommending considerations for do-it-yourself (DIY) tDCS (Wurzman et al., 2016), including the involvement of healthcare professionals. A workshop hosted by the United States Institute of Medicine (IOM) addressed clinical and non-clinical applications of $\mathrm{tDCS}$, including available evidence, safety, and ethics (Bain et al., 2015).

While tDCS can broadly modulate brain activity, and is considered safe within accepted boundaries, it remains to be conclusively determined whether it can improve sports performance at an elite level. The ability to optimize muscle control and maximize speed, power or duration is crucial to many sports, as is training and motivation (Crewther et al., 2016). In pursuit of excellence, athletes already use holistic approaches that directly or indirectly influence the brain. Some of these 
approaches include: meditation and visualization (Rich et al., 2016), and acupuncture (Ahmedov, 2010), which can have central effects (Zhu et al., 2015). Other holistic techniques include music to reduce the perception of physical effort (Jarraya et al., 2012) and psychological tools for motivation or harnessing placebo effects (Sabino-Carvalho et al., 2016).

Many athletes implement at least one of these tools; which, while not scientifically proven in all cases, are considered safe. tDCS may be yet another example (Figure 1).

Okano et al. studied the effects of $20 \mathrm{~min}$ of tDCS with the anode over the left temporal cortex (T3) on trained cyclists (Okano et al., 2013) during an incremental cycling test, and found significantly improved peak power, as well as reduced heart rate and perception of effort at submaximal workloads. Clarke et al. evaluated the effects of tDCS on a perceptual-learning paradigm (object detection in a simulated combat environment), showing significant enhancement of threat-detection accuracy with tDCS with the anode over the right inferior frontal cortex (Clark et al., 2012). In both cases, performance benefits were at least partially attributed to the effects of tDCS on perception (reduced fatigue and improved threat detection). Angius et al. (2016) likewise reported reduced perception of effort and increased endurance in 9 cyclists following anodal stimulation of the motor cortex (M1) when the cathode was placed on the contralateral shoulder but not when placed over the prefrontal region. Similarly, Borducchi et al. (2016), found that elite athletes gained a potential competitive advantage in cognitive performance and mood elevation, with $2 \mathrm{~mA}$ of tDCS with the anode over the left dorsolateral prefrontal cortex. By contrast, Flood et al. (2017) noted that while high definition tDCS targeting the sensorimotor cortex reduced perception of pain during fatiguing lower limb exercise in 12 subjects, there was no significant effect on muscle endurance or maximal production of force (Flood et al., 2017). There have been further positive (Cogiamanian et al., 2007; Abdelmoula et al., 2016) and negative (Kan et al., 2013; Muthalib et al., 2013) reports on the effects of tDCS with the anode over M1 on isolated muscle groups, such as the elbow flexor, and it is important to consider how post-exercise measurement of a unique muscle group in non-athletes might relate to conditions of athletic performance (Angius et al., 2017). Uncontrolled application of tDCS includes the US Olympic ski team (Reardon,
2016), top-tiered NBA team (Mansfield, 2016) and gamers (Falcone and Parasuraman, 2012; Jarrett, 2016). No doubt, the performance of these pioneering athletes will be followed carefully.

In a recent paper on athletic performance stagnation, Berthelot et al. (2015) questioned the extent to which athletic capabilities would progress beyond the boundaries of human physiological limitations. They conjectured, however, that technological breakthroughs might mitigate factors that limit physical performance. One such potential factor is perception of effort, which can be modulated by tDCS over M1, resulting in reduced perception of effort and greater endurance (Vitor-Costa et al., 2015). Fatigue contributes not only to reduced muscular endurance (Williams et al., 2013), but can also impair decision-making, response time and skill (Rattray et al., 2015). In addition, tDCS can enhance motor learning (Reis et al., 2009) thereby increasing the benefit of practice and promoting better performance. It is possible to hypothesize the mechanisms of action of tDCS which could lead to athletic performance enhancement; however, such hypotheses need careful testing before broad adoption.

One challenge for research scientists is to determine the efficacy of tDCS in real-world sports performance, and assess its safety in the context of repeated use. Additional questions remain regarding results found in laboratory conditions vs. field events and in athletes vs. healthy non-athletes; or improvements in strength vs. endurance, and upper extremity augmentation with tDCS juxtaposed with tDCS enhancement to lower extremities. A challenge for sports authorities is to determine where tDCS supplementation fits into the regulatory framework at the elite level. In the meantime, it seems likely that tDCS will continue to be explored by competitive athletes looking for that elusive edge. In the presence of media attention (Dubljević et al., 2014; Batuman, 2015) and marketing, it is likely that tDCS direct-to-consumer usage will expand. This engenders engagement from the scientific community. When and how are we obligated to step in as scientists? Is it desirable to learn from uncontrolled adoption in a form of crowdsourced science (see Wexler, 2016; Wexler and Hamilton, 2017)? To what extent are companies marketing consumer

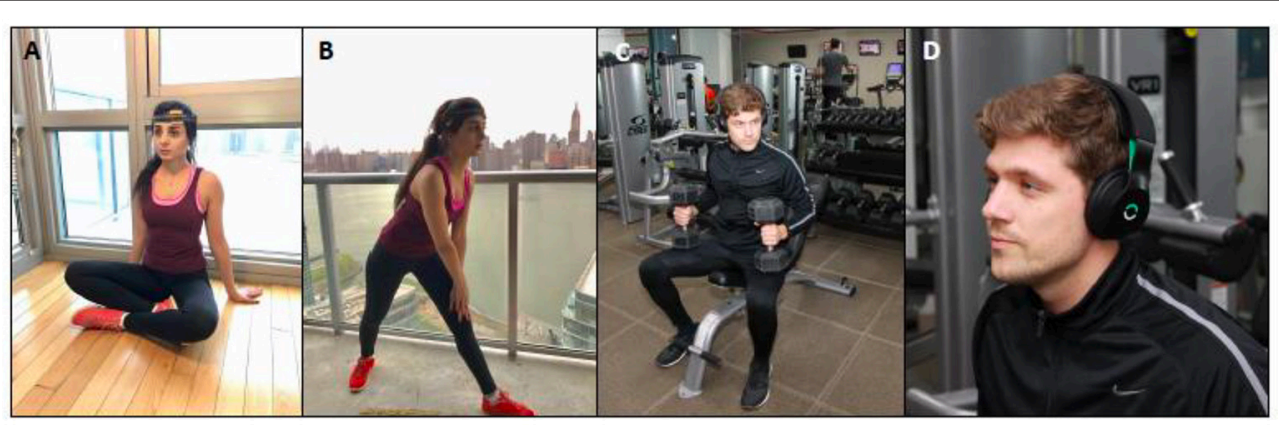

FIGURE 1 | Examples of tDCS device being used in sports training. (A,B) Caputron tDCS device. (C,D) Halo tDCS device. Devices are typically used for 20 min before intensive training when motion is minimized, then removed when intensive physical training begins, comparable to timing in clinical rehabilitation. 
products for sports performance beholden to the scientific community? Notwithstanding these complex questions, ongoing controlled experiments of tDCS in sports performance is of high value.

\section{AUTHOR CONTRIBUTIONS}

All authors listed, have made substantial, direct and intellectual contribution to the work, and approved it for publication.

\section{REFERENCES}

Abdelmoula, A., Baudry, S., and Duchateau, J. (2016). Anodal transcranial direct current stimulation enhances time to task failure of a submaximal contraction of elbow flexors without changing corticospinal excitability. Neuroscience 322, 94-103. doi: 10.1016/j.neuroscience.2016.02.025

Ahmedov, S. (2010). Ergogenic effect of acupuncture in sport and exercise: a brief review. J. Strength Condit. Res. 24, 1421-1427. doi: 10.1519/JSC.0b013e3181d156b1

Angius, L., Hopker, J., and Mauger, A. R. (2017). The ergogenic effects of transcranial direct current stimulation on exercise performance. Front. Physiol. 8:90. doi: 10.3389/fphys.2017.00090

Angius, L., Pageaux, B., Hopker, J., Marcora, S. M., and Mauger, A. R. (2016). Transcranial direct current stijulation improves isometric time to exhaustion of the knee extensors. Neuroscience 339, 363-375. doi: 10.1016/j.neuroscience.2016.10.028

Bain, L., Norris, S., and Stroud, C. (2015). Non-invasive Neuromodulation of the Central Nervous System: Opportunities and Challenges: Workshop Summary. Washington, DC: National Academies Press. doi: 10.17226/21767

Batuman, E. (2015). ELECTRIFIED Adventures in Transcranial DirectCurrent Stimulation. New Yorker. [online] Available online at: http://www.newyorker.com/magazine/2015/04/06/electrified (Accessed April 6, 2015).

Baudewig, J., Nitsche, M. A., Paulus, W., and Frahm, J. (2001). Regional modulation of BOLD MRI responses to human sensorimotor activation by transcranial direct current stimulation. Magn. Reson. Med. 45, 196-201. doi: 10.1002/1522-2594(200102)45:2<196::AID-MRM1026>3.0.CO;2-1

Berthelot, G., Sedeaud, A., Marck, A., Antero-Jacquemin, J., Schipman, J., Saulière, G., et al. (2015). Has athletic performance reached its peak? Sports Med. 45, 1263-1271. doi: 10.1007/s40279-015-0347-2

Bikson, M., Grossman, P., Thomas, C., Zannou, A., Jiang, J., and Adnan, T. (2016b). Safety of transcranial direct current stimulation: evidence based update 2016. Brain Stimul. 9, 641-661. doi: 10.1016/j.brs.2016.06.004

Bikson, M., Paneri, B., and Giordano, J. (2016a). The off-label use, utility and potential value of tDCS in the clinical care of particular neuropsychiatric conditions. J. Law Biosci. 3, 642-646. doi: 10.1093/jlb/lsw044

Borducchi, D., Gomes, J. S., Akiba, H., Cordeiro, Q., Borducchi, J. M., Valentin, L., et al. (2016). Transcranial direct current stimulation effects on athletes' cognitive performance: an exploratory proof of concept trial. Front. Psychiatry 7:183. doi: $10.3389 /$ fpsyt.2016.00183

Clark, V., Coffman, B., Mayer, A., Weisend, M., Lane, T., Calhoun, V., et al. (2012). TDCS guided using fMRI significantly accelerates learning to identify concealed objects. NeuroImage 59, 117-128. doi: 10.1016/j.neuroimage.2010.11.036

Cogiamanian, F., Marceglia, S., Ardolino, G., Barbieri, S., and Priori, A. (2007). Improved isometric force endurance after transcranial direct current stimulation over the human motor cortical areas. Eur. J. Neurosci. 26, 242-249. doi: 10.1111/j.1460-9568.2007.05633.x

Crewther, B., Carruthers, J., Kilduff, L., Sanctuary, C., and Cook, C. (2016). Temporal associations between individual changes in hormones, training motivation and physical performance in elite and non-elite trained men. Biol. Sport 33, 215-221. doi: 10.5604/20831862.1201810

\section{FUNDING}

This work was supported by the NIMH, NINDA, and NICHD of the NIH, under award numbers R01HD069776, 1R01NS10136201, 1R01MH111896-01, 1R01NS095123-01, 1R01MH109289-01. AP was partly supported by the Sidney R. Baer Jr. Foundation, the NIH (R01MH100186, R01HD069776, R01NS073601, R21 NS082870, R21 MH099196, R21 NS085491, R21 HD07616), the Football Players Health Study at Harvard University, and Harvard Catalyst|The Harvard Clinical and Translational Science Center (NCRR and the NCATS NIH, UL1 RR025758).

Datta, A., Bansal, V., Diaz, J., Patel, J., Reato, D., and Bikson, M. (2009). Gyri precise head model of transcranial DC stimulation: improved spatial focality using a ring electrode versus conventional rectangular pad. Brain Stimul. 2, 201-207. doi: 10.1016/j.brs.2009.03.005

DosSantos, M. F., Love, T. M., Martikainen, I. K., Nascimento, T. D., Fregni, F., Cummiford, C., et al. (2012). Immediate effects of tDCS on the $\mu$-opioid system of a chronic pain patient. Front. Psychiatry 3:93. doi: 10.3389/fpsyt.2012.00093

Dubljević, V., Saigle, V., and Racine, E. (2014). The rising tide of tDCS in the media and academic literature. Neuron 82, 731-736. doi: 10.1016/j.neuron.2014.05.003

Edwards, D., Cortes, M., Datta, A., Minhas, P., Wassermann, E. M., and Bikson, M. (2013). Physiological and modeling evidence for focal transcranial electrical brain stimulation in humans: a basis for high-definition tDCS. NeuroImage 74, 266-275. doi: 10.1016/j.neuroimage.2013.01.042

Falcone, B., and Parasuraman, R. (2012). Comparative effects of firstperson shooter video game experience and brain stimulation on threat detection learning. Proc. Hum. Fact. Ergon. Soc. Ann. Meeting 56, 173-177. doi: $10.1177 / 1071181312561013$

Flood, A., Waddington, G., Keegan, R. J., Thompson, K. G., and Cathcart, S. (2017). The effects of elevated pain inhibition on endurance exercise performance. PeerJ 5:e3028. doi: 10.7717/peerj.3028

Fregni, F., Nitsche, M., Loo, C. K., Brunoni, A., Marangolo, P., Leite, J., et al. (2015). Regulatory considerations for the clinical and research use of transcranial direct current stimulation (tDCS): review and recommendations from an expert panel. Clin. Res. Regul. Aff. 32, 22-35. doi: 10.3109/10601333.2015.980944

Hamner, J., Villamar, M., Fregni, F., and Taylor, J. (2015). Transcranial direct current stimulation (tDCS) and the cardiovascular responses to acute pain in humans. Clin. Neurophysiol. 126, 1039-1046. doi: 10.1016/j.clinph.2014.08.019

Huang, Y., Liu, A. A., Lafon, B., Friedman, D., Dayan, M., Wang, X., et al. (2017). Measurements and models of electric fields in the in vivo human brain during transcranial electric stimulation. eLife 6:e18834. doi: 10.7554/eLife.18834

Janssens, A. C., and Kraft, P. (2012). Research conducted using data obtained through online communities: ethical implications of methodological limitation. PLoS Med. 9:e1001328. doi: 10.1371/journal.pmed.1001328

Jarraya, M., Chtourou, H., Aloui, A., Hammouda, O., Chamari, K., Chaouachi, A., et al. (2012). The effects of music on high-intensity short-term exercise in well trained athletes. Asian J. Sports Med. 3, 233-238. doi: 10.5812/asjsm.34543

Jarrett, C. (2016). Read This Before Zapping Your Brain Online. Available online at: https://www.wired.com/2014/01/read-zapping-brain/ (Accessed January 20, 2014).

Jog, M., Smith, R., Jann, K., Dunn, W., Lafon, B., and Truong, D. (2016). In-vivo imaging of magnetic fields induced by transcranial direct current stimulation (tDCS) in human brain using MRI. Sci. Rep. 6:34385. doi: 10.1038/srep34385

Kan, B., Dundas, J. E., and Nosaka, K. (2013). Effect of transcranial direct current stimulation on elbow flexor maximal voluntary isometric strength and endurance. Appl. Physiol. Nutr. Metab. 38, 734-739. doi: 10.1139/apnm-2012-0412

Kuersten, A., and Hamilton, R. (2016). Minding the "gaps" in the federal regulation of transcranial direct current stimulation devices. J. Law Biosci. 3, 309-317. doi: 10.1093/jlb/lsw015

Luu, P., Essaki Arumugam, E., Anderson, E., Gunn, A., Rech, D., and Turovets, S. (2016). Slow-frequency pulsed transcranial electrical stimulation for 
modulation of cortical plasticity based on reciprocity targeting with precision electrical head modelling. Front. Hum. Neurosci. 10:377. doi: 10.3389/fnhum.2016.00377

Mansfield, A. (2016). Do the Warriors Owe Some of Their Success to These "Brain-Zapping" Headphones? New York, NY: Complex.

Muthalib, M., Kan, B., Nosaka, K., and Perrey, S. (2013). Effects of transcranial direct current stimulation of the motor cortex on prefrontal cortex activation during a neuromuscular fatigue task: an fNIRS study. Adv. Exp. Med. Biol. 789, 73-79. doi: 10.1007/978-1-4614-7411-1_11

Nitsche, M. A., and Paulus, W. (2000). Excitability changes induced in the human motor cortex by weak transcranial direct current stimulation. J. Physiol. 527(Pt 3), 633-639. doi: 10.1111/j.1469-7793.2000.t01-100633.x

Okano, A., Fontes, E., Montenegro, R., Farinatti, P., Cyrino, E., Li, L., et al. (2013). Brain stimulation modulates the autonomic nervous system, rating of perceived exertion and performance during maximal exercise. Br. J. Sports Med. 49, 1213-1218. doi: 10.1136/bjsports-2012-091658

Rattray, B., Argus, C., Martin, K., Northey, J., and Driller, M. (2015). Is it time to turn our attention toward central mechanisms for post-exertional recovery strategies and performance? Front. Physiol. 6:79. doi: 10.3389/fphys.2015. 00079

Reardon, S. (2016). 'Brain doping' may improve athletes' performance. Nature 531, 283-284. doi: 10.1038/nature.2016.19534

Reis, J., Schambra, H., Cohen, L., Buch, E., Fritsch, B., Zarahn, E., et al. (2009). Noninvasive cortical stimulation enhances motor skill acquisition over multiple days through an effect on consolidation. Proc. Natl. Acad. Sci. U.S.A. 106, 1590-1595. doi: 10.1073/pnas.0805413106

Rich, T., Pfister, R., Alton, J., Gerdt, D., and Baruch, M. (2016). Assessment of Cardiovascular parameters during meditation with mental targeting in varsity swimmers. Evidence Based Complement. Altern. Med. 2016, 1-5. doi: $10.1155 / 2016 / 7923234$

Sabino-Carvalho, J., Lopes, T., Freitas, T., Ferreira, T., Succi, J., Silva, A., et al. (2016). Effect of ischemic preconditioning on endurance performance does not surpass placebo. Med. Sci. Sports Exerc. 49, 124-132. doi: 10.1249/MSS.0000000000001088

Strube, W., Bunse, T., Nitsche, M., Nikolaeva, A., Palm, U., Padberg, F., et al. (2016). Bidirectional variability in motor cortex excitability modulation following $1 \mathrm{~mA}$ transcranial direct current stimulation in healthy participants. Physiol. Rep. 4:e12884. doi: 10.14814/phy2. 12884

Vitor-Costa, M., Okuno, N., Bortolotti, H., Bertollo, M., Boggio, P., Fregni, F., et al. (2015). Improving cycling performance: transcranial direct current stimulation increases time to exhaustion in cycling. PLoS ONE 10:e144916. doi: 10.1371/journal.pone.0144916

Wagner, S., Lucka, F., Vorwerk, J., Herrmann, C. S., Nolte, G., Burger, M., et al. (2016). Using reciprocity for relating the simulation of transcranial current stimulation to the EEG forward problem. Neuroimage 140, 163-173. doi: 10.1016/j.neuroimage.2016.04.005

Wexler, A. (2016). The practices of do-it-yourself brain stimulation: implications for ethical considerations and regulatory proposals. J. Med. Ethics 42, 211-215. doi: 10.1136/medethics-2015-102704

Wexler, A., and Hamilton, R. (2017). Crowdsourced tDCS research: feasible or fanciful? AJOB Neurosci. 8, 50-53. doi: 10.1080/21507740.2017.1288176

Williams, P., Hoffman, R., and Clark, B. (2013). Preliminary evidence that anodal transcranial direct current stimulation enhances time to task failure of a sustained submaximal contraction. PLOS ONE 8:e81418. doi: 10.1371/journal.pone.0081418

Woods, A., Antal, A., Bikson, M., Boggio, P., Brunoni, A., Celnik, P., et al. (2016). A technical guide to tDCS, and related non-invasive brain stimulation tools. Clin. Neurophysiol. 127, 1031-1048. doi: 10.1016/j.clinph.2015.11.012

Wurzman, R., Hamilton, R., Pascual-Leone, A., and Fox, M. (2016). An open letter concerning do-it-yourself users of transcranial direct current stimulation. Ann. Neurol. 80, 1-4. doi: 10.1002/ana.24689

Zettler, P. J. (2016). What lies ahead for FDA regulation of tDCS products? J. Law Biosci. 3, 318-323. doi: 10.1093/jlb/lsw024

Zhu, B., Wang, Y., Zhang, G., Ouyang, H., Zhang, J., Zheng, Y., et al. (2015). Acupuncture at KI3 in healthy volunteers induces specific cortical functional activity: an fMRI study. BMC Complement. Altern. Med. 15:361. doi: 10.1186/s12906-015-0881-3

Disclosure: The content is solely the responsibility of the authors and does not necessarily represent the official views of Harvard Catalyst, Harvard University and its affiliated academic health care centers, the National Institutes of Health, or the Sidney R. Baer Jr. Foundation.

Conflict of Interest Statement: AP serves on the scientific advisory boards for Nexstim, Neuronix, Starlab Neuroscience, Neuroelectrics, Axilum Robotics, Magstim Inc., and Neosync; and is listed as an inventor on several issued and pending patents on the real-time integration of transcranial magnetic stimulation with electroencephalography and magnetic resonance imaging.

The other authors declare that the research was conducted in the absence of any commercial or financial relationships that could be construed as a potential conflict of interest.

Copyright (c) 2017 Edwards, Cortes, Wortman-Jutt, Putrino, Bikson, Thickbroom and Pascual-Leone. This is an open-access article distributed under the terms of the Creative Commons Attribution License (CC BY). The use, distribution or reproduction in other forums is permitted, provided the original author (s) or licensor are credited and that the original publication in this journal is cited, in accordance with accepted academic practice. No use, distribution or reproduction is permitted which does not comply with these terms. 